\title{
Efficacy and safety of moxifloxacin in community acquired pneumonia: a prospective, multicenter, observational study (CAPRIVI)
}

Ilija Kuzman ${ }^{1 *}$, Alexandr Bezlepko², Irena Kondova Topuzovska ${ }^{3}$, László Rókusz ${ }^{4}$, Liudmyla ludina ${ }^{5}$, Hans-Peter Marschall ${ }^{6}$ and Thomas Petri ${ }^{7}$

\begin{abstract}
Background: Community acquired pneumonia (CAP) is a major cause of morbidity, hospitalization, and mortality worldwide. Management of CAP for many patients requires rapid initiation of empirical antibiotic treatment, based on the spectrum of activity of available antimicrobial agents and evidence on local antibiotic resistance. Few data exist on the severity profile and treatment of hospitalized CAP patients in Eastern and Central Europe and the Middle East, in particular on use of moxifloxacin $\left(\right.$ Avelox $\left.^{\oplus}\right)$, which is approved in these regions.

Methods: CAPRIVI (Community Acquired Pneumonia: tReatment wlth AVelox ${ }^{\circledast}$ in hospltalized patients) was a prospective observational study in 12 countries: Croatia, France, Hungary, Kazakhstan, Jordan, Kyrgyzstan, Lebanon, Republic of Moldova, Romania, Russia, Ukraine, and Macedonia. Patients aged $>18$ years were treated with moxifloxacin $400 \mathrm{mg}$ daily following hospitalization with a CAP diagnosis. In addition to efficacy and safety outcomes, data were collected on patient history and disease severity measured by CRB-65 score.

Results: 2733 patients were enrolled. A low severity index (i.e., CRB-65 score <2) was reported in 87.5\% of CAP patients assessed ( $n=1847)$, an unexpectedly high proportion for hospitalized patients. Moxifloxacin administered for a mean of 10.0 days (range: 2.0 to 39.0 days) was highly effective: $96.7 \%$ of patients in the efficacy population $(n=2152)$ improved and $93.2 \%$ were cured of infection during the study. Severity of infection changed from "moderate" or "severe" in $91.8 \%$ of patients at baseline to "no infection" or "mild" in 95.5\% at last visit. In the safety population ( $n=2595), 127$ (4.9\%) patients had treatment-emergent adverse events (TEAEs) and 40 (1.54\%) patients had serious TEAEs; none of these 40 patients died. The safety results were consistent with the known profile of moxifloxacin.
\end{abstract}

Conclusions: The efficacy and safety profiles of moxifloxacin at the recommended dose of $400 \mathrm{mg}$ daily are characterized in this large observational study of hospitalized CAP patients from Eastern and Central Europe and the Middle East. The high response rate in this study, which included patients with a range of disease severities, suggests that treatment with broader-spectrum drugs such as moxifloxacin is appropriate for patients with CAP who are managed in hospital.

Trial registration: ClinicalTrials.gov identifier: NCT00987792

Keywords: Antibiotics, Pneumonia, Community acquired, CAP, Moxifloxacin

\footnotetext{
* Correspondence: ilijakuzman@net.hr

'University of Zagreb School of Medicine, University Hospital for Infectious Diseases "Dr. Fran Mihaljević", Mirogojska cesta 8, 10000 Zagreb, Croatia Full list of author information is available at the end of the article
} 


\section{Background}

Community acquired pneumonia (CAP) is one of the most common infectious diseases worldwide [1]. Reported incidences of CAP in different countries range from 1.6 to 11 per 1000 adults, although precise estimates are difficult to establish, in part because no universal definition exists for diagnosing CAP [2].

CAP is a major cause of morbidity, hospitalization, mortality, and impaired quality of life, and associated with substantial societal health care burden. In Western European countries, the rate of hospitalization of patients with CAP varies between approximately $10 \%-60 \%$, depending largely on the patient group under investigation [3-9]. Mortality rates of CAP range from $<5 \%$ in outpatients to $10 \%$ in ward patients, and exceed $30 \%$ in patients in intensive care, illustrating the broad spectrum of severity of the disease [10]. Incidences of CAP and CAP-related mortality increase sharply with age, and are appreciably higher in men than women $[9,11]$.

The main causative pathogens in CAP are Streptococcus pneumoniae, Haemophilus influenzae, and Moraxella catarrhalis, which together account for approximately $85 \%$ of cases [12]. Additional "atypical" pathogens in CAP include Mycoplasma pneumoniae, Chlamydophila pneumoniae, and Legionella pneumophila. Many CAP patients have mixed infections including both typical and atypical pathogens [13].

Instant diagnosis of the causative organism would be optimal for managing CAP; however, the responsible pathogen is usually not known at the time of CAP diagnosis and no pathogen is identified in up to $50 \%$ of patients even after extensive testing for several days [14]. Since rapid initiation of antibiotic treatment of CAP is mandatory, an empirical antibiotic therapy is required taking into consideration the spectrum of efficacy of available agents and local evidence on antimicrobial resistance [15]. Guidelines on empirical treatment from the Infectious Disease Society of America (IDSA)/American Thoracic Society (ATS) recommend an antipneumococcal fluoroquinolone (e.g., moxifloxacin or levofloxacin) or a combination of $\beta$-lactam and macrolide for CAP patients hospitalized on a general ward [15]. The guidelines of the European Respiratory Society also recommend moxifloxacin or levofloxacin as a treatment option for empirical therapy for hospitalized CAP patients with or without the need of intensive care [16].

Moxifloxacin is a fourth-generation fluoroquinolone with a broad spectrum of activity against microorganisms isolated in CAP, including multi-resistant pneumococci and pathogens such as M. catarrhalis and $H$. influenzae with resistance to penicillins, macrolides, and tetracyclines. Moxifloxacin also possesses activity against atypical pathogens including L. pneumophila, C. pneumoniae, and M. pneumoniae [17-20].
Moxifloxacin at the recommended dose of $400 \mathrm{mg}$ once daily has been investigated in prospective, randomized, double-blind clinical trials and meta-analyses in patients with mild, moderate, and severe CAP in community- and hospital-based settings (e.g., [21-32]).

Moxifloxacin is generally very well tolerated by patients, with low incidences of adverse events in clinical and post-marketing studies [33]. A meta-analysis that included 14 randomized controlled trials, consisting of 6923 patients, confirmed that moxifloxacin is as effective and well tolerated as other recommended antibiotics in treating CAP and has a pathogen eradication rate superior to $\beta$-lactam-based therapy [32]. Studies in CAP patients also show that moxifloxacin reduces length of hospital stay compared with standard therapies, with potential significant cost savings $[34,35]$.

Most moxifloxacin studies in CAP have been randomized trials, but observational studies also provide valuable information relevant to practice [36].

The primary objective of the current observational study - the CAPRIVI (Community Acquired Pneumonia: tReatment wIth AVelox in hospItalized patients) study was to evaluate the distribution of CRB-65 severity index at baseline in patients hospitalized with CAP. The CRB-65 is a validated tool for risk evaluation that can be used for rapid selection of treatment strategies in CAP. The reliability of the CRB-65 has been confirmed in more than 5000 patients in Western Europe and Asia, mostly in hospitalized patients or patients seen initially in emergency departments [37-42]. The distribution of CRB-65 scores has not previously been reported in hospitalized CAP patients from South Eastern Europe, the Community of Independent States, or the Middle East.

The majority of moxifloxacin studies have been conducted in Western Europe or Northern America, where intravenous moxifloxacin has been available for a number of years. Secondary objectives of the CAPRIVI study were to collect data on the efficacy and safety of moxifloxacin in CAP from South Eastern Europe, the Community of Independent States, or the Middle East, where data from routine practice have not previously been collected. Patients from France were included in the CAPRIVI study, since intravenous moxifloxacin has only recently become available in this country.

\section{Methods}

\section{Study design}

The CAPRIVI study was a prospective, multicenter, observational study conducted at 247 investigational centers in 12 countries: Croatia, France, Hungary, Kazakhstan, Jordan, Kyrgyzstan, Lebanon, Republic of Moldova, Romania, Russia, Ukraine, and Macedonia, between September 15, 2009 and June 20, 2011. 
The study consisted of an assessment at baseline and an observational period between the initiation and completion of treatment with moxifloxacin $\left(\right.$ Avelox $\left.^{\circ}\right)$ in patients hospitalized with CAP. One, or at most two, follow-up study visits were planned for each patient after the initial assessment.

\section{Patients and investigators}

Male or female patients aged 18 years and above who were hospitalized with a diagnosis of CAP were included in the study after the decision to prescribe moxifloxacin was made by treating physicians. The decision to prescribe moxifloxacin was made by physicians based on their medical judgment and in accordance with the locally available Summary of Product Characteristics for moxifloxacin. The diagnosis of CAP and any concomitant diseases was based on local medical practice.

The majority of patients $(85.5 \%, \mathrm{n}=1840 / 2152)$ entered hospital on the first day of moxifloxacin therapy; $45.2 \%$ of patients were hospitalized as emergency cases and $43.6 \%$ were referred to hospital. Patients were most frequently treated in the pneumology unit (54.3\%), followed by internal medicine (20.0\%) and infectious disease units (10.3\%). No information on the treating unit was given in the remaining cases.

Study exclusion criteria were limited to the contraindications to the use of moxifloxacin as described in the local product information. Use of a concomitant anti-infective treatment was an additional exclusion criterion. Data on disease characteristics and risk factors were collected from patients before the initiation of moxifloxacin treatment.

The study protocol was approved by the local independent ethics committee or institutional review board, as applicable in each country. Committee and review board approvals were provided as follows: Croatia: the National Ethics Committee (EC); France: the EC of the National Council of Physicians; Hungary: the National Ethics Committee; Kazakhstan: the EC of the National Center of Expertise of Medicinal Drugs, Medical Equipment and Items of Medical Utility; Kyrgyzstan: the Department of Drug Provision and Medical Equipment under the Ministry of Health of the Kyrgyz Republic; Macedonia: the EC for Medical Trials from the Medical Faculty in Skopje as well by the Commission for Clinical Trials of the National Drug Agency; Republic of Moldova: the Ministry of Health; Romania: the National Agency for Medicines and Medical Devices and the National EC for the Clinical Study of Medicines; Russia: the National Intercollegiate EC; and Ukraine: the Central Ethics Committee of Ministry of Health. No EC approval was required in the Lebanon and Jordan at the time this study was conducted. All patients provided written, informed consent at the start of the study, in accordance with and as required by local regulations.
Centralized risk-based study monitoring and quality review Data fabrication is a rare form of scientific misconduct in clinical trials, but when it does occur it has serious consequences [43]. Non-interventional trials may be even more prone to data fabrication, since quality assurance has only recently been introduced for observational studies [44]. Data fabrication was considered to be the highest risk to the data quality of this study. This is one of the first non-interventional studies where quality assurance procedures (described below) were used to detect data falsification.

The US Food and Drug Administration (FDA) recently published recommendations on centralized monitoring practices, which should improve a sponsor's ability to ensure the quality of trial data [45]. It is surprisingly hard to fabricate data without leaving all kinds of statistical clues that can be detected from the data [46].

A set of central monitoring and biostatistical testing procedures tailored to the study protocol were implemented to identify investigational centers suspicious for fraudulent activity. Tests were implemented, for example, to detect a very large number of recruited patients, multiple patients enrolled on the same day, multiple patients with the same pattern of follow-up visits, a short duration of recruitment in relation to the number of the recruited patients, low numbers of queries and low numbers of missing data per patient, low numbers of adverse events per patient, low numbers of patients lost to follow up, and obvious similarities in laboratory values. These tests compared the site performance relative to all other sites. Points were given per test depending on the quartile that the site fell into and whether the upper or lower quartile was suspicious for fraudulent activity. These points were summed to calculate the fraud score for each site. The higher the score, the higher was the risk that falsified data were submitted by the site.

Focusing on centers with a high fraud score, telephone interviews were conducted with a set of predefined questions to decide whether a suspicion of fraud could or could not be rejected. The interviews were carefully documented and the results were evaluated by the interviewers and study managers. All patients from sites where the suspicion of fraudulent activity could not be rejected during the telephone interview were excluded from analysis.

\section{Study medication}

Moxifloxacin contains a C-8 methoxy substitute that increases bactericidal activity, decreases the risk of selecting resistant mutants, and enhances activity against Grampositive bacteria [47]. Moxifloxacin has beneficial pharmacokinetic and pharmacodynamic properties, is strongly targeted to alveolar tissue, and demonstrates rapid initial killing with high eradication rates [48]. 
Moxifloxacin was prescribed in accordance with guidelines from the European Medicines Agency, the FDA, and local regulations (e.g., AVELOX ${ }^{\ominus}$ [moxifloxacin hydrochloride] Summary of Product Characteristics) [49,50].

The dose of moxifloxacin recommended for treatment of CAP in the study was $400 \mathrm{mg}$ once every 24 hours, consistent with the local Summary of Product Characteristics. Moxifloxacin could be administered exclusively as intravenous therapy or as sequential therapy consisting of intravenous followed by oral administration. The method of administration of moxifloxacin was selected by the treating physician. The recommended duration of moxifloxacin therapy for CAP in guidelines is 7 to 14 days, depending on the severity of disease and clinical response. Final decisions on the dose and duration of moxifloxacin therapy and on the use of concomitant medications were made by the attending physician.

\section{Efficacy and safety assessments}

The primary study objective was assessment of the distribution of CRB-65 score at baseline. The CRB-65 score was calculated by awarding one point each for the following: presence of mental confusion, respiratory rate $\geq 30$ breaths/ min, systolic blood pressure $<90 \mathrm{mmHg}$ or diastolic blood pressure $\leq 60 \mathrm{mmHg}$, and aged $\geq 65$ years $[5,37,51-53]$. The mortality rate in patients with a CRB- 65 score of 0 is below $1 \%$, with a score of $1-2$ about $5 \%$ and with a score of 3 or 4 up to $25 \%$. Patients with a CRB-65 score of 3 or 4 should be considered for urgent hospital admission [40].

Additional efficacy assessments, performed at the initial visit and the last follow-up visit after moxifloxacin therapy, included standard diagnostic measures in daily practice: chest radiography, blood laboratory tests, core body temperature, and microbiologic tests; clinical signs and symptoms including dyspnea, cough, sputum character, and thoracic pain (classified as "relieved", "improved", "unchanged" or "worsened" vs baseline); and the overall condition of the patient and overall severity of infection as judged by the physician. Time to improvement, rate of cure (i.e., a return to the status prior to onset of CAP), time to hospital discharge, physicians' rating of symptom improvement, and patients' satisfaction with moxifloxacin therapy were also assessed.

Safety and tolerability were assessed by treatment-emergent adverse events (TEAEs) reported during the study, coded using the Medical Dictionary for Regulatory Activities (MedDRA) version 15.0, and categorized by seriousness and relationship to treatment, the frequency of premature discontinuations of moxifloxacin therapy, referral rates, and hospitalizations due to failure of therapy.

\section{Statistical analyses}

Efficacy and safety analyses were exploratory and observational, as appropriate for non-interventional studies.
Categorical and quantitative (continuous) data were analyzed by descriptive statistics including means, standard deviations (SDs), and minimum and maximum values. Non-missing data are presented throughout.

The efficacy population included all patients who took at least one dose of study medication and provided information on the efficacy of treatment. The safety population included all patients who received at least one dose of study medication and provided information on adverse events.

According to sample size calculations, 2655 patients were required to be included for analysis of the main study objectives.

\section{Results}

\section{Centralized risk-based study monitoring and quality review}

From a total of 253 sites, the 14 centers with the highest fraud scores were selected for telephone interviews. Two of these 14 centers were excluded because they were unwilling to be interviewed by telephone. For two other centers, the suspicion of fraud could not be rejected from the answers given during the telephone interview, e.g., because the patient files were not available to provide answers to prespecified questions. These four centers, with a total of 135 patients, were therefore excluded from data analysis. In the remaining 10 centers, plausible answers were received and the source data were available for review. Thus the suspicion of fraud was rejected for these latter centers and their data were included in the analyses.

\section{Patient population}

A total of 2733 patients were enrolled in the study. Of these, 135 patients (as mentioned above) were excluded because their recruiting site failed to pass quality review. Three additional patients were excluded because data were not available on moxifloxacin intake, leaving 2595 patients for inclusion in the safety population. Of these 2595 patients, 443 were excluded from the efficacy population, in the majority of cases $(n=296)$ because of concomitant other anti-infective treatment, leaving 2152 patients evaluable for efficacy (Figure 1).

Demographic and disease characteristics of the efficacy population are described in Table 1. Patient ages ranged from 18 to 100 years (mean $53.3 \pm 17.9$ years), with $29.2 \%$ of patients aged above 65 years. More men (56.7\%) than women participated in the study, while White patients constituted the majority (85.2\%). Over one third of patients were documented as past $(12.8 \%)$ or current (23.3\%) smokers.

The majority of patients $(71.8 \%)$ had received no vaccination, neither against pneumococcus nor against influenza. A pneumonia episode in the previous 12 months 


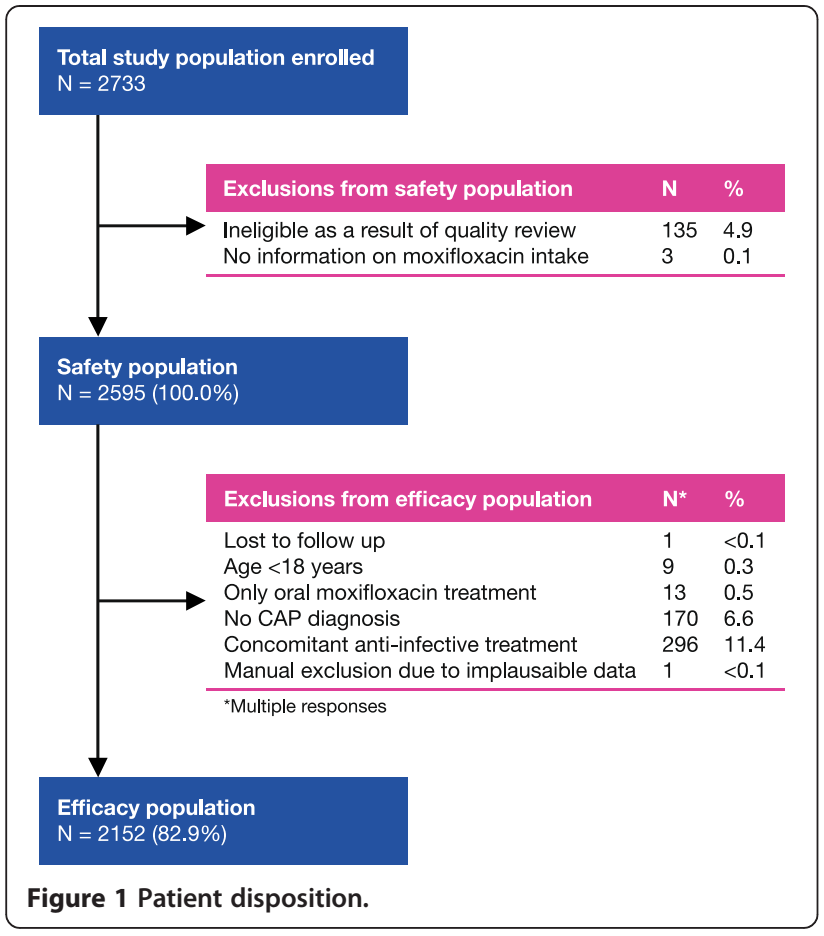

was reported by $8.7 \%$ of patients. Among the patients hospitalized in the last 12 months (14.8\% of the efficacy population), $35.1 \%$ named CAP as the reason for hospitalization (Table 1).

All patients were hospitalized in the current study because of a diagnosis of CAP, and no patients were hospitalized for concomitant disease. One or more concomitant diseases were reported by $70.4 \%$ of patients. A risk factor for CAP or a prespecified concomitant disease of special interest was recorded in $56.5 \%$ of patients, including: chronic obstructive pulmonary disease (31.7\% of patients), cardiac ischemia (18.1\%), diabetes mellitus $(9.7 \%)$, congestive heart failure (8.4\%), and asthma (7.5\%). One or more concomitant medications were taken by $79.5 \%$ of patients. As expected, the majority of these patients (71.2\%) received concomitant medication for the respiratory system. The mucolytic ambroxol/ambroxol hydrochloride was the most frequently used medication (27.9\% of all patients), followed by paracetamol (14.2\%), acetylcysteine (11.6\%), and furosemide (10.1\%).

A previous antibiotic had been administered to $41.4 \%$ of patients within 14 days before starting moxifloxacin therapy, most commonly amoxicillin (with or without clavulanic acid), ceftriaxone, or azithromycin. Patients were switched to moxifloxacin for the current CAP episode most frequently because of a lack of efficacy with the previous antibiotic (87.3\%).

Patients experienced CAP symptoms for a mean (SD) of $5.0 \pm 3.8$ days (range, 0.0-35.0 days) before the start of moxifloxacin therapy. The majority of patients (85.5\%)
Table 1 Patient demographics and disease characteristics (efficacy population)

\begin{tabular}{|c|c|}
\hline Parameter & Total $\mathrm{N}=2152(100 \%)$ \\
\hline \multicolumn{2}{|l|}{ Gender, n (\%) } \\
\hline Male & $1220(56.7)$ \\
\hline Female & $918(42.7)$ \\
\hline Missing & $14(0.7)$ \\
\hline Mean (SD) age, y $(n=2136)$ & $53.3(17.9)$ \\
\hline Mean (SD) weight, kg $(n=2117)$ & $77.3(15.0)$ \\
\hline Mean (SD) height, cm $(n=2099)$ & $170.9(9.0)$ \\
\hline Mean (SD) BMl, kg/m² $(n=2098)$ & $26.5(4.8)$ \\
\hline \multicolumn{2}{|l|}{ Race, n (\%) } \\
\hline White & $1833(85.2)$ \\
\hline Asian & $119(5.5)$ \\
\hline Black & $3(0.1)$ \\
\hline Other & $4(0.2)$ \\
\hline Missing & $193(9.0)$ \\
\hline \multicolumn{2}{|l|}{ Smoking status, n (\%) } \\
\hline Non-smoker & $1331(61.8)$ \\
\hline Present smoker & $501(23.3)$ \\
\hline Past smoker & $276(12.8)$ \\
\hline Missing & $44(2.0)$ \\
\hline \multicolumn{2}{|l|}{ Type of vaccination, n (\%) } \\
\hline None & $1546(71.8)$ \\
\hline Pneumococcus & $8(0.4)$ \\
\hline Influenza & $237(11.0)$ \\
\hline Both & $18(0.8)$ \\
\hline Missing & $343(15.9)$ \\
\hline \multicolumn{2}{|c|}{ Pneumonia episodes in past 12 months } \\
\hline Yes & $187(8.7)$ \\
\hline No & $1838(85.4)$ \\
\hline Unknown & $81(3.8)$ \\
\hline Missing & $46(2.1)$ \\
\hline \multicolumn{2}{|l|}{ Hospitalization in past 12 months } \\
\hline Yes & $319(14.8)$ \\
\hline Due to CAP & $112(35.1)$ \\
\hline Other & $178(55.8)$ \\
\hline Missing & $40(12.5)$ \\
\hline No & $1740(80.9)$ \\
\hline Unknown & $53(2.5)$ \\
\hline Missing & $40(1.9)$ \\
\hline
\end{tabular}

started moxifloxacin on the day of hospitalization (Table 2). Most patients were hospitalized as emergency cases $(45.2 \%)$ or referred by physicians (43.6\%), with another $7.2 \%$ of patients self-referred and $2.9 \%$ already hospitalized. 
Table 2 Duration between day of hospitalization and start of moxifloxacin therapy (efficacy population)

\begin{tabular}{lcc}
\hline $\begin{array}{l}\text { Duration } \\
\text { (days) }\end{array}$ & \multicolumn{2}{c}{ Total $\mathbf{N}=\mathbf{2 1 5 2}(\mathbf{1 0 0 . 0 \% )}$} \\
\hline 0 & $\mathbf{n}$ & (\%) \\
\hline 1 & 1840 & $(85.5)$ \\
2 & 107 & $(5.0)$ \\
3 & 55 & $(2.6)$ \\
4 & 46 & $(2.1)$ \\
5 & 32 & $(1.5)$ \\
6 & 36 & $(1.7)$ \\
Missing & 34 & $(1.1)$ \\
\hline
\end{tabular}

\section{Baseline assessments}

\section{CRB-65 score}

Distributions of CRB-65 scores were as follows: $55.1 \%$ of patients scored 0, 32.4\% scored 1, 8.2\% scored 2, 4.0\% scored 3, and $0.3 \%$ scored 4 (Figure 2). On categorizing patients into groups based on low or high severity index (i.e., CRB-65 score $<2$ vs $\geq 2$ ), $87.5 \%$ of patients ( $95 \%$ confidence interval $[\mathrm{CI}], 86.0-89.0)$ had a low index and 12.5\% (95\% CI, 11.0-14.0) had a high index.

Considering the individual CRB-65 score components, mental confusion was present in $8.6 \%$ of patients, respiratory rate $\geq 30$ breaths $/ \mathrm{min}$ in $7.2 \%$, systolic blood pressure $<90 \mathrm{mmHg}$ or diastolic blood pressure $\leq 60 \mathrm{mmHg}$ in $14.0 \%$, and age $\geq 65$ years in $29.2 \%$ of patients.

\section{Diagnostic measures}

Chest radiography was performed at the initial visit in $98.9 \%$ of patients, showing at least one of the following: unilateral infiltrate in $76.0 \%$ of patients, bilateral infiltrate

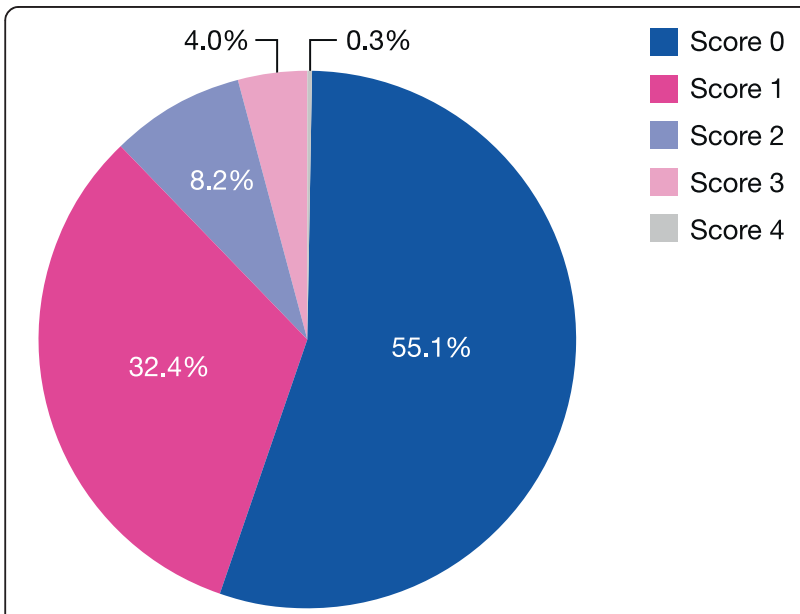

Figure 2 Distribution of CRB-65 scores in study population at baseline. in $19.8 \%$, pleural effusion in $6.7 \%$, and multilobar involvement in $4.3 \%$. A normal lung appearance was observed in $0.7 \%$. In these latter cases as well as in those with a CAP diagnosis without a confirmatory chest radiograph, CAP was diagnosed by other procedures, according to the physicians' experience. Mean (SD) laboratory test results in patients with available data were: C-reactive protein: $109.6 \pm 267.1 \mathrm{mg} / \mathrm{L}(\mathrm{n}=766)$, arterial blood partial pressure of oxygen: $66.6 \pm 14.3 \mathrm{mmHg}(\mathrm{n}=484)$, blood $\mathrm{pH}$ : $7.41 \pm 0.07 \quad(\mathrm{n}=774)$, and oxygen saturation: $91.9 \pm 5.7$ $(\mathrm{n}=1459)$. The mean (SD) value for white blood count was $11.6 \pm 5.8 \mathrm{giga} / \mathrm{L}(\mathrm{n}=2120) ; 67(3.1 \%)$ of patients had a WBC count of $<4$ giga/L (3.1\%) and 1054 (49.0\%) had a WBC count of $>11$ giga/L.

Microorganisms were isolated/diagnosed in 507 (23.6\%) patients. Methods for the isolation/diagnosis of microorganisms included (use of more than one method was possible): culture of respiratory secretions (48.0\% of cases), blood culture (16.5\%), blood serology (9.2\%), or urinary antigen (2.6\%). The method was not recorded for $42.8 \%$ of patients who had microorganisms isolated/diagnosed.

The microorganisms isolated/diagnosed included $S$. pneumoniae in $10.1 \%$ of patients, $H$, influenzae in $4.2 \%$, Staphylococcus aureus in $2.9 \%$, C. pneumoniae in $1.8 \%$, M. pneumoniae in $1.5 \%$, L. pneumophila in $1.1 \%$, M. catarrhalis in $0.9 \%$, and Enterobacteriaceae/ "Other" in $5.2 \%$. Rates of phenotypic resistance in the microorganisms are described in Table 3.

\section{Moxifloxacin treatment}

The majority of patients treated with moxifloxacin $(83.7 \%)$ received sequential intravenous followed by oral administration, and the remainder received exclusively intravenous treatment. In total, $97.1 \%$ of patients in the sequential treatment group and $99.7 \%$ in the intravenous treatment group received the recommended daily dose of $400 \mathrm{mg}$ moxifloxacin. No information on the daily dose was given for $2.9 \%$ and $0.3 \%$ of patients in the respective groups. The mean duration of moxifloxacin treatment until symptom improvement or treatment discontinuation was $10.0 \pm 3.0$ days (range, 2.0-39.0 days) in the combined group, consisting of $10.5 \pm 2.7$ days in the sequential treatment group (mean 4.1 days for intravenous and 6.5 days for oral administration) and $7.3 \pm$ 3.2 days in the intravenous treatment group.

\section{Assessments during moxifloxacin treatment}

In total, $84.8 \%$ of patients had two follow-up visits. The mean (SD) duration between the start of moxifloxacin therapy and the first and second follow-up visits was $4.7 \pm 3.6$ days and $11.0 \pm 5.2$ days, respectively. The last follow-up visit was a mean of $10.6 \pm 5.5$ days after the initiation of moxifloxacin therapy. 
Table 3 Phenotypic resistance of isolated microorganisms (efficacy population)

\begin{tabular}{|c|c|c|c|c|}
\hline \multirow{2}{*}{$\frac{\text { Microorganism }}{\text { Streptococcus pneumoniae }}$} & \multicolumn{4}{|c|}{ Resistance status } \\
\hline & Penicillin- $\mathrm{R}^{*}$ & Penicillin-I* & Penicillin-S* & Not available \\
\hline$n=217(100 \%)$ & 27/217 (12.4\%) & $2 / 217(2.3 \%)$ & $69 / 217(31.8 \%)$ & $116 / 217(53.5 \%)$ \\
\hline Haemophilus influenzae & $\beta$-lactamase pos. & - & $\beta$-lactamase neg. & Not available \\
\hline$n=90(100 \%)$ & $6 / 90(6.7 \%)$ & & $20 / 90(22.2 \%)$ & $64 / 90(71.3 \%)$ \\
\hline Moraxella catarrhalis & $\beta$-lactamase pos. & - & $\beta$-lactamase neg. & Not available \\
\hline$n=19(100 \%)$ & $2 / 19(10.5 \%)$ & & $3 / 19(15.8 \%)$ & 15/19 (73.7\%) \\
\hline Staphylococcus aureus & MRSA & - & MSSA & Not available \\
\hline \multirow[t]{3}{*}{$\mathrm{n}=62(100 \%)$} & $2 / 62(3.2 \%)$ & & $17 / 62(21.4 \%)$ & $41 / 62(66.1 \%)$ \\
\hline & Oxacillin-R & & Oxacillin-S & \\
\hline & $0 / 62(0 \%)$ & & $2 / 62(3.2 \%)$ & \\
\hline Enterobacteriaceae spp. & ESBL producer & - & Non-ESBL producer & Not available \\
\hline$n=211(100 \%)$ & 2/111 (1.8\%) & & 11/111 (9.9\%) & 98/111 (88.3\%) \\
\hline
\end{tabular}

${ }^{*} \mathrm{R}, \mathrm{I}, \mathrm{S}=$ resistant, intermediate resistant, sensitive, respectively. ESBL, extended-spectrum $\beta$-lactamase; MRSA, methicillin-resistant Staphylococcus aureus; MSSA, methicillin-sensitive Staphylococcus aureus.

\section{Course of signs and symptoms}

The overall condition of patients changed from primarily "serious" or "critical" (68.1\% of patients) at the initial visit to mainly "good" or "fair" (97.6\%) at the last visit (Table 4). The severity of infection changed from "moderate" or "severe" in the majority of patients (91.8\%) to "no infection" or "mild" in most (95.5\%) at the last visit. Improvements in the severity of dyspnea, cough, sputum character, and thoracic pain and in rates of abnormal auscultation, core temperature, and chest radiography are shown in Table 4.

Symptoms were rated as "relieved" or "improved" over the course of therapy in the majority of patients for dyspnea $(95.3 \%)$, cough $(93.3 \%)$, sputum character $(94.7 \%)$, thoracic pain (95.8\%), and auscultation (84.2\%) (Table 5). Symptoms were unchanged in a small number of patients (ranging from $2.1 \%$ for thoracic pain to $11.8 \%$ for auscultation) and worsening of symptoms was reported in a very small proportion (ranging from $0.1 \%$ for auscultation to $1.3 \%$ for temperature).

The mean core temperature was $39.2^{\circ} \mathrm{C} \pm 0.9^{\circ} \mathrm{C}$ (range: $36.0^{\circ} \mathrm{C}$ to $42.0^{\circ} \mathrm{C}$ ) at baseline visit and $37.5^{\circ} \mathrm{C} \pm 0.5^{\circ} \mathrm{C}$ (range: $36.0^{\circ} \mathrm{C}$ to $40.9^{\circ} \mathrm{C}$ ) at the last visit. A return to normal temperature (i.e., $\leq 37.5^{\circ} \mathrm{C}$ ) occurred at a mean of $2.8 \pm 1.5$ days (Table 6). Temperature was rated as "relieved" or "improved" in the majority of patients (84.8\%) from the initial to the last visit.

\section{Time to improvement and cure rates}

In total, $96.7 \%$ of patients in the efficacy population were reported to improve, i.e., feel better, during the study, while only $2.8 \%$ did not improve (Figure 3 ). Improvement was achieved in $78.9 \%$ of patients after 3 days, $88.3 \%$ after 4 days, and $94.4 \%$ after 5 days. The mean duration until improvement was $2.7 \pm 1.3$ days.
Cure of infection was reported in $93.2 \%$ of patients at the end of therapy, versus $5.2 \%$ who were not cured (data were missing in $1.6 \%$ of patients). Stratified analyses by symptoms, diagnostic measures, vital signs, and previous antibiotic use at baseline identified no substantial differences in the rate of cure of CAP between subgroups. Cure rates in patients with mild, moderate, or severe infection, for example, were 94.3\%, 94.6\%, and $89.6 \%$, respectively.

\section{Time to hospital discharge}

A total of $93.2 \%$ of patients were discharged from hospital after a mean of $10.4 \pm 5.9$ days of moxifloxacin therapy. Stratified analysis showed that duration of hospitalization was longer in patients with a higher CRB-65 score at baseline (mean 13.5 and 10.4 days for scores of $\geq 2$ and $<2$, respectively) and in patients who did not versus who did achieve a cure by moxifloxacin (mean 15.5 and 10.2 days). The most frequently identified reasons why patients were not discharged from hospital were concomitant diseases $(0.6 \%)$ and failure of moxifloxacin therapy $(0.3 \%)$.

\section{Safety assessments}

Moxifloxacin was well tolerated, with low rates of TEAEs and serious TEAEs. Between the initial visit and the last follow-up visit, there were 171 TEAEs documented in 127 (4.9\%) of the 2595 patients in the safety population. In the judgment of investigators, 109/171 TEAEs (63.7\%; in 87 patients) were related to moxifloxacin treatment. Drug-related TEAEs (in $\geq 0.10 \%$ of the safety population) included diarrhea (1.23\% of patients), nausea $(0.50 \%)$, urticaria $(0.19 \%)$, dizziness $(0.15 \%)$, dysgeusia $(0.15 \%)$, and headache $(0.12 \%)$. No hepatic side effects and no serious skin lesions were reported. 
Table 4 Investigations at initial and follow-up visits (efficacy population)

\begin{tabular}{|c|c|c|c|c|c|c|c|c|}
\hline \multirow{3}{*}{ Investigations } & \multicolumn{8}{|c|}{ Visits } \\
\hline & \multicolumn{2}{|c|}{ Initial } & \multicolumn{2}{|c|}{ 1st follow-up } & \multicolumn{2}{|c|}{ 2nd follow-up } & \multicolumn{2}{|c|}{ Last } \\
\hline & $\mathrm{n}$ & (\%) & $\mathrm{n}$ & (\%) & $\mathrm{n}$ & (\%) & $\mathbf{n}$ & $(\%)$ \\
\hline \multicolumn{9}{|l|}{ Patient's condition } \\
\hline Total patients & 2152 & $(100.0)$ & 2139 & $(100.0)$ & 1824 & $(100.0)$ & 2139 & $(100.0)$ \\
\hline Missing & 2 & $(0.1)$ & 5 & $(0.2)$ & 7 & $(0.4)$ & 9 & $(0.4)$ \\
\hline Good & 65 & (3.0) & 713 & (33.3) & 1349 & $(74.0)$ & 1549 & $(72.4)$ \\
\hline Fair & 619 & $(28.8)$ & 1230 & $(57.5)$ & 439 & $(24.1)$ & 539 & $(25.2)$ \\
\hline Serious & 1385 & $(64.4)$ & 176 & $(8.2)$ & 21 & $(1.2)$ & 31 & (1.4) \\
\hline Critical & 81 & (3.8) & 15 & $(0.7)$ & 8 & $(0.4)$ & 11 & $(0.5)$ \\
\hline \multicolumn{9}{|c|}{ Severity of infection } \\
\hline Total patients & 2152 & $(100.0)$ & 2139 & $(100.0)$ & 1824 & $(100.0)$ & 2139 & $(100.0)$ \\
\hline Missing & 2 & $(0.1)$ & 5 & $(0.2)$ & 14 & $(0.8)$ & 15 & $(0.7)$ \\
\hline No infection & 0 & $(-)$ & 339 & $(15.8)$ & 1482 & (81.3) & 1670 & $(78.1)$ \\
\hline Mild & 174 & $(8.1)$ & 1174 & (54.9) & 277 & $(15.2)$ & 373 & (17.4) \\
\hline Moderate & 1378 & $(64.0)$ & 565 & $(26.4)$ & 32 & (1.8) & 54 & $(2.5)$ \\
\hline Severe & 598 & $(27.8)$ & 56 & (2.6) & 19 & $(1.0)$ & 27 & (1.3) \\
\hline \multicolumn{9}{|l|}{ Dyspnea } \\
\hline Total patients & 2152 & $(100.0)$ & 2139 & $(100.0)$ & 1824 & $(100.0)$ & 2139 & $(100.0)$ \\
\hline Missing & 7 & $(0.3)$ & 13 & $(0.6)$ & 12 & $(0.7)$ & 15 & $(0.7)$ \\
\hline None & 283 & (13.2) & 932 & (43.6) & 1488 & (81.6) & 1679 & (78.5) \\
\hline Mild & 546 & $(25.4)$ & 896 & $(41.9)$ & 279 & (15.3) & 381 & $(17.8)$ \\
\hline Moderate & 959 & $(44.6)$ & 269 & (12.6) & 32 & (1.8) & 46 & $(2.2)$ \\
\hline Severe & 357 & $(16.6)$ & 29 & (1.4) & 13 & $(0.7)$ & 18 & $(0.8)$ \\
\hline \multicolumn{9}{|l|}{ Cough } \\
\hline Total patients & 2152 & $(100.0)$ & 2139 & $(100.0)$ & 1824 & $(100.0)$ & 2139 & $(100.0)$ \\
\hline Missing & 6 & $(0.3)$ & 7 & $(0.3)$ & 11 & $(0.6)$ & 11 & $(0.5)$ \\
\hline None & 49 & $(2.3)$ & 335 & $(15.7)$ & 1067 & (58.5) & 1177 & $(55.0)$ \\
\hline Mild & 321 & $(14.9)$ & 1115 & $(52.1)$ & 672 & (36.8) & 850 & (39.7) \\
\hline Moderate & 1142 & (53.1) & 638 & $(29.8)$ & 70 & (3.8) & 93 & $(4.3)$ \\
\hline Severe & 634 & $(29.5)$ & 44 & $(2.1)$ & 4 & $(0.2)$ & 8 & $(0.4)$ \\
\hline \multicolumn{9}{|l|}{ Sputum character } \\
\hline Total patients & 2152 & $(100.0)$ & 2139 & $(100.0)$ & 1824 & $(100.0)$ & 2139 & $(100.0)$ \\
\hline Missing & 4 & $(0.2)$ & 8 & $(0.4)$ & 12 & $(0.7)$ & 13 & $(0.6)$ \\
\hline None & 338 & $(15.7)$ & 582 & $(27.2)$ & 1202 & $(65.9)$ & 1344 & $(62.8)$ \\
\hline Clear & 151 & $(7.0)$ & 713 & (33.3) & 489 & (26.8) & 602 & (28.1) \\
\hline Mucoid & 783 & $(36.4)$ & 713 & (33.3) & 110 & $(6.0)$ & 161 & $(7.5)$ \\
\hline Purulent & 876 & $(40.7)$ & 123 & (5.8) & 11 & $(0.6)$ & 19 & $(0.9)$ \\
\hline \multicolumn{9}{|l|}{ Thoracic pain } \\
\hline Total patients & 2152 & (100.0) & 2139 & $(100.0)$ & 1824 & $(100.0)$ & 2139 & $(100.0)$ \\
\hline Missing & 11 & $(0.5)$ & 18 & $(0.8)$ & 15 & $(0.8)$ & 18 & $(0.8)$ \\
\hline None & 696 & (32.3) & 1416 & $(66.2)$ & 1686 & $(92.4)$ & 1918 & (89.7) \\
\hline Mild & 554 & $(25.7)$ & 539 & $(25.2)$ & 98 & (5.4) & 166 & (7.8) \\
\hline Moderate & 775 & $(36.0)$ & 154 & $(7.2)$ & 21 & $(1.2)$ & 31 & (1.4) \\
\hline Severe & 116 & (5.4) & 12 & $(0.6)$ & 4 & $(0.2)$ & 6 & $(0.3)$ \\
\hline
\end{tabular}


Table 4 Investigations at initial and follow-up visits (efficacy population) (Continued)

\begin{tabular}{|c|c|c|c|c|c|c|c|c|}
\hline \multicolumn{9}{|l|}{ Auscultation } \\
\hline Total patients & 2152 & $(100.0)$ & 2139 & $(100.0)$ & 1824 & $(100.0)$ & 2139 & $(100.0)$ \\
\hline Missing & 27 & (1.3) & 74 & (3.5) & 48 & (2.6) & 63 & (2.9) \\
\hline Normal & 84 & (3.9) & 794 & (37.1) & 1591 & $(87.2)$ & 1821 & $(85.1)$ \\
\hline Pathological & 2041 & $(94.8)$ & 1271 & $(59.4)$ & 185 & $(10.1)$ & 255 & $(11.9)$ \\
\hline \multicolumn{9}{|l|}{ Core temperature* } \\
\hline Total patients & 2152 & $(100.0)$ & 2139 & $(100.0)$ & 1824 & $(100.0)$ & 2139 & $(100.0)$ \\
\hline Missing & 30 & (1.4) & 93 & (4.3) & 156 & (8.6) & 187 & $(8.7)$ \\
\hline Low & 0 & $(-)$ & 1 & $(<0.1)$ & 0 & $(-)$ & 0 & $(-)$ \\
\hline Normal & 77 & (3.6) & 552 & (25.8) & 628 & $(34.4)$ & 724 & (33.8) \\
\hline Mild & 147 & (6.8) & 848 & (39.6) & 936 & (51.3) & 1052 & $(49.2)$ \\
\hline Moderate & 531 & $(24.7)$ & 585 & (27.3) & 93 & (5.1) & 159 & $(7.4)$ \\
\hline Severe & 1367 & $(63.5)$ & 60 & (2.8) & 11 & (0.6) & 17 & $(0.8)$ \\
\hline \multicolumn{9}{|l|}{ Chest radiography** } \\
\hline Total patients & 2152 & $(100.0)$ & 2139 & $(100.0)$ & 1824 & $(100.0)$ & 2139 & $(100.0)$ \\
\hline Missing & 14 & $(0.7)$ & 51 & (2.4) & 16 & $(0.9)$ & 31 & (1.4) \\
\hline Not done & 8 & (0.4) & 1230 & $(57.5)$ & 397 & $(21.8)$ & 483 & $(22.6)$ \\
\hline Normal & 16 & $(0.7)$ & 292 & (13.7) & 1178 & $(64.6)$ & 1299 & $(60.7)$ \\
\hline Pleural effusion & 144 & (6.7) & 41 & (1.9) & 24 & (1.3) & 27 & (1.3) \\
\hline Unilateral infiltrate & 1635 & $(76.0)$ & 425 & (19.9) & 178 & (9.8) & 263 & $(12.3)$ \\
\hline Bilateral infiltrate & 427 & (19.8) & 114 & (5.3) & 34 & (1.9) & 41 & (1.9) \\
\hline Multilobar involvement & 92 & (4.3) & 18 & $(0.8)$ & 11 & (0.6) & 12 & $(0.6)$ \\
\hline
\end{tabular}

${ }^{*}$ Comparison of temperature ranges: Low: $<36.0^{\circ} \mathrm{C}$, Normal: $36.0^{\circ} \mathrm{C}-<37.5^{\circ} \mathrm{C}$, Mild: $37.5^{\circ} \mathrm{C}-<38.0^{\circ} \mathrm{C}$, Moderate: $38.0^{\circ} \mathrm{C}-<39.0^{\circ} \mathrm{C}$, Severe: $\geq 39.0^{\circ} \mathrm{C}$;

**Multiple responses.

In total, 110/171 TEAEs (in 87 patients) resolved during the study, two TEAEs (one patient) resolved with sequelae, 12 TEAEs (10 patients) were resolving, and four TEAEs (three patients) were unresolved. TEAEs were rated serious on 62 occasions (40 patients), based on classifications including "necessary or prolonged hospitalization" (31 patients), "fatal outcome" (31 patients), "important medical event" (four patients), "life-threatening event" (four patients), and "disability/incapacity" (one patient). Of the 62 serious events, 11 were classified as drug-related (seven patients). Twenty-seven TEAEs (19 patients) were fatal; none of the fatal TEAEs were considered drug-related.

No change in moxifloxacin dose was required for 72/171 (42.1\%) TEAEs; moxifloxacin was completely withdrawn for 36 TEAEs (21.2\%) and was interrupted (with subsequent resumption of moxifloxacin after TEAEs had ceased) for 31 TEAEs (18.1\%). Moxifloxacin therapy was prematurely discontinued in $3.3 \%$ of patients $(n=72)$, mainly owing to adverse events $(n=34)$, lack of efficacy $(n=24)$, and bacterial resistance $(n=6)$. Another antibiotic for

Table 5 Course of clinical signs and symptoms from initial to last follow up visit (efficacy population)

\begin{tabular}{|c|c|c|c|c|c|c|c|c|c|c|c|c|}
\hline \multirow{2}{*}{$\begin{array}{l}\text { Course of } \\
\text { symptoms }\end{array}$} & \multicolumn{2}{|c|}{ Dyspnea } & \multicolumn{2}{|c|}{ Cough } & \multicolumn{2}{|c|}{ Sputum character } & \multicolumn{2}{|c|}{ Thoracic pain } & \multicolumn{2}{|c|}{ Auscultation } & \multicolumn{2}{|c|}{ Temperature* } \\
\hline & $\mathrm{n}$ & (\%) & $\mathrm{n}$ & (\%) & $\mathrm{n}$ & (\%) & $n$ & $(\%)$ & $\mathrm{n}$ & (\%) & $n$ & $(\%)$ \\
\hline Total & 2152 & $(100.0)$ & 2152 & $(100.0)$ & 2152 & $(100.0)$ & 2152 & $(100.0)$ & 2152 & $(100.0)$ & 2152 & $(100.0)$ \\
\hline Relieved & 1677 & (77.9) & 1174 & $(54.6)$ & 1343 & $(62.4)$ & 1914 & $(88.9)$ & 1811 & $(84.2)$ & 722 & (33.6) \\
\hline Improved & 374 & (17.4) & 832 & $(38.7)$ & 695 & $(32.3)$ & 148 & $(6.9)$ & 0 & $(-)$ & 1101 & $(51.2)$ \\
\hline Unchanged & 61 & $(2.8)$ & 104 & (4.8) & 65 & (3.0) & 45 & $(2.1)$ & 253 & (11.8) & 98 & (4.6) \\
\hline Worsened & 9 & $(0.4)$ & 13 & (0.6) & 21 & $(1.0)$ & 10 & $(0.5)$ & 2 & $(0.1)$ & 28 & $(1.3)$ \\
\hline Missing & 31 & (1.4) & 29 & (1.3) & 28 & (1.3) & 35 & (1.6) & 86 & $(4.0)$ & 203 & $(9.4)$ \\
\hline
\end{tabular}

${ }^{*}$ Comparison of temperature ranges: Low: $<36.0^{\circ} \mathrm{C}$, Normal: $36.0^{\circ} \mathrm{C}-<37.5^{\circ} \mathrm{C}$, Mild: $37.5^{\circ} \mathrm{C}-<38.0^{\circ} \mathrm{C}$, Moderate: $38.0^{\circ} \mathrm{C}-<39.0^{\circ} \mathrm{C}$, Severe: $\geq 39.0^{\circ} \mathrm{C}$. 
Table 6 Duration until return to normal temperature (efficacy population)

\begin{tabular}{lcccc}
\hline \multirow{2}{*}{$\begin{array}{l}\text { Duration until } \leq \mathbf{3 7 . 5} \mathbf{5}^{\circ} \mathbf{C} \\
\text { (days) }\end{array}$} & \multicolumn{4}{c}{ Total $\mathbf{N}=\mathbf{2 1 5 2}(\mathbf{1 0 0 \% )}$} \\
\cline { 2 - 5 } & $\mathbf{n}^{*}$ & $(\%)$ & $\mathbf{n}$ cum & (\%) cum \\
\hline 1 & 273 & $(14.4)^{* *}$ & 273 & $(12.7)$ \\
2 & 656 & $(34.6)^{* *}$ & 929 & $(43.2)$ \\
3 & 557 & $(29.4)^{* *}$ & 1486 & $(69.1)$ \\
4 & 214 & $(11.3)^{* *}$ & 1700 & $(79.0)$ \\
5 & 116 & $(6.1)^{* *}$ & 1816 & $(84.4)$ \\
6 & 30 & $(1.6)^{* *}$ & 1846 & $(85.8)$ \\
7 & 27 & $(1.4)^{* *}$ & 1873 & $(87.0)$ \\
8 & 7 & $(0.4)^{* *}$ & 1880 & $(87.4)$ \\
9 & 5 & $(0.3)^{* *}$ & 1885 & $(87.6)$ \\
10 & 8 & $(0.4)^{* *}$ & 1893 & $(88.0)$ \\
11 & 2 & $(0.1)^{* *}$ & 1895 & $(88.1)$ \\
20 & 1 & $(0.1)^{* *}$ & 1896 & $(88.1)$ \\
No return to normal T & 37 & $(1.7)$ & 1933 & $(89.8)$ \\
Patient not febrile at start & 189 & $(8.8)$ & & \\
T not taken continuously & 12 & $(0.6)$ & & \\
Missing & 19 & $(0.9)$ & & \\
Total & 2152 & $(100.0)$ & 2152 & $(100.0)$ \\
\hline
\end{tabular}

*Multiple responses; **Percentage of total return to normal temperature $(n=1896)$.

$\mathrm{T}$, temperature.

treatment of CAP was initiated in $5.5 \%$ of patients ( $\mathrm{n}=119)$ following moxifloxacin.

\section{Physicians' rating of symptom improvement and patients' satisfaction with moxifloxacin therapy}

Physicians rated the symptoms of CAP as either "very much improved" or "much improved" in 95.3\% of patients (Figure 4a). Minimal improvement, or no change in symptoms, was recorded in $3.1 \%$, and a worsening of symptoms in $1.0 \%$ of patients. Stratified analysis showed that the symptoms of CAP were improved less in patients with increasing age or coexisting risk factors.

Physicians reported that $94.1 \%$ of patients were "very much satisfied" or "much satisfied" with moxifloxacin therapy (Figure 4b). Minimal satisfaction, or indifference to therapy, was reported by $3.9 \%$ and dissatisfaction by $0.8 \%$ of patients.

\section{Discussion}

This non-interventional, naturalistic, observational study evaluated the baseline CRB-65 status and the efficacy and safety of moxifloxacin treatment in 2733 enrolled patients hospitalized with a current episode of CAP. A notable feature of this study is the well-documented patient history including previous episodes of CAP, vaccination history, concomitant diseases, and co-medications. Another notable feature in this observational study is the use of quality assurance measures to confirm the validity of the data analyzed, leading to the exclusion of approximately $5 \%$ of the originally included patients since the suspicion of data falsification by the investigators could not be excluded. Although this led to a reduction in the overall number of the patients, the data quality of the remaining patient population was thereby increased. To our knowledge, this is one of the first non-interventional studies where quality assurance procedures were used to detect data falsification.

Reflecting current clinical experience, the microorganisms isolated most frequently were $S$. pneumoniae (including penicillin-resistant strains), $H$. influenzae (including $\beta$-lactamase producing strains), and atypical pathogens. Almost one-half of patients (41.4\%) had received an antibiotic treatment in the previous 14 days for their current CAP episode before starting moxifloxacin therapy. The majority of these patients were switched to moxifloxacin because of a lack of efficacy with the previous antibiotic.

The primary objective of CAPRIVI was the distribution of the CRB-65 score at baseline. In this population,

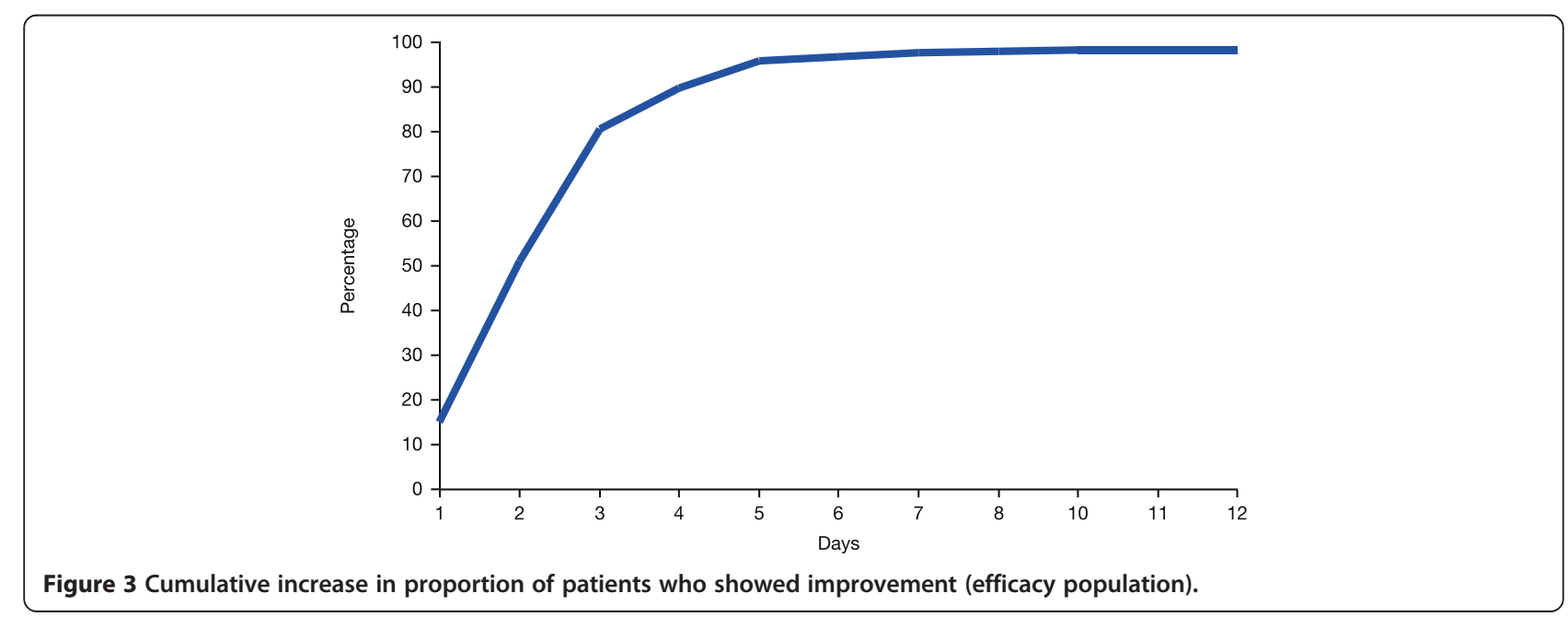




\section{a}

b
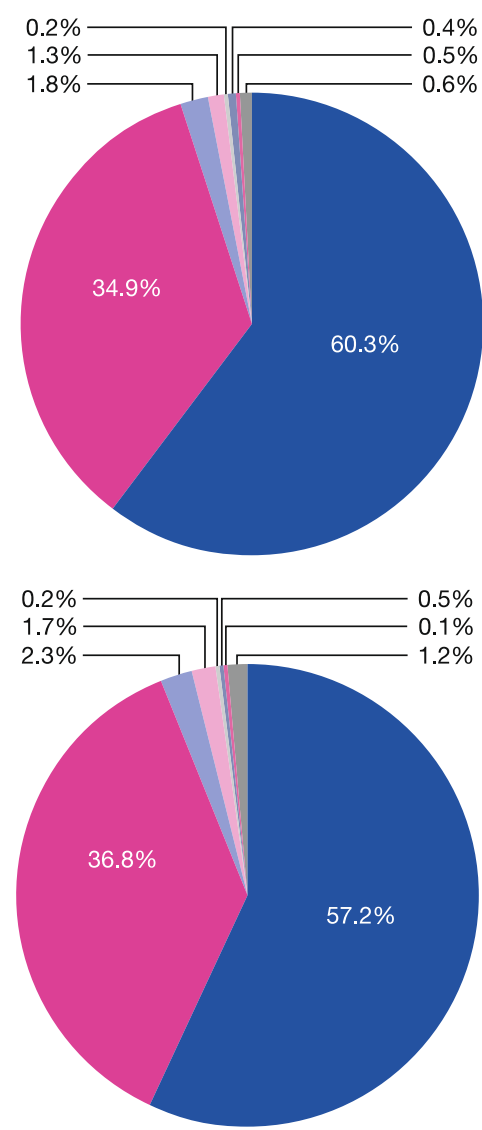

Very much improved

Much improved

Minimally impoved

No change

Minimally worse

Much worse

Very much worse

Missing
Very much satisfied

Much satisfied

Minimally satisfied

Neither satisfied nor dissatisfied

Minimally dissatisfied

Much dissatisfied

Very much dissatisfied

Missing

Figure 4 Assessments of improvement and satisfaction. (a) Physicians' rating of improvement during moxifloxacin therapy; (b) patients' satisfaction with moxifloxacin therapy (efficacy population).

87.5\% of hospitalized patients had a CRB-65 score 0 or 1 , while only $12.5 \%$ had a score 2 to 4 . It had been predicted that a greater proportion of the patients would have a CRB-65 score of 2 or above, since a high score is a strong indicator for hospitalization. This study suggests that a large proportion of CAP patients are hospitalized in the participating countries who would be treated at home according to current international recommendations $[5,40]$. Potential explanations for this unexpected finding may include a high rate of failure of previous alternative antibiotic therapy (which occurred in $41.4 \%$ of patients), as well as differences in health care systems, such as a reluctance of primary care physicians to treat CAP patients in their homes, social circumstances that required greater rates of hospitalization, greater severity of underlying medical diseases in this study population, and the lower hospital costs in Eastern and South Eastern Europe versus Western Europe. The predictive power of the CRB-65 score for CAP-associated mortality appears to be supported in this study, as the mortality rate of hospitalized patients in the CAPRIVI study $(<1 \%)$ was substantially lower than in hospitalized patients in the USA $(10 \%-14 \%)$ and corresponds to the mortality rate in US patients treated in the community [54].

Moxifloxacin at a dose of $400 \mathrm{mg}$ once daily for a mean of 10.0 days (range, 2.0-39.0 days) was a highly effective treatment in CAP patients. Improvements were reported in a range of diagnostic measures routinely used in clinical practice, including the patient's overall condition, severity of infection, symptoms of dyspnea, cough, sputum, and thoracic pain, and rates of abnormal auscultation, core temperature, and chest radiography. In total, $96.7 \%$ of patients experienced an improvement, i.e., felt better during the study. Improvements occurred after a mean of 2.7 days, and over $94 \%$ of patients had experienced an improvement after 5 days; $93.2 \%$ of patients were reported cured of infection by the end of therapy. No differences in the efficacy of moxifloxacin were observed between patients who received moxifloxacin by intravenous administration alone or by sequential intravenous then oral administration. Also, no differences in the efficacy of 
moxifloxacin were observed between patients experiencing a range of disease severities at baseline.

In recent years, the susceptibility of typical pathogens to penicillins, macrolides, trimethoprim/sulfamethoxazole, and second-generation cephalosporins has decreased, so that multidrug-resistant strains causing CAP are of increasing clinical relevance [7,25,55]. It is notable that, despite this trend, moxifloxacin was effective in a large proportion of patients in this study.

Unlike in interventional trials, the moxifloxacin dosing regimen used in this non-interventional study was left to the discretion of the treating physician. It is interesting to note the high rate of physician compliance with the moxifloxacin dose recommended in the Summary of Product Characteristics (i.e., $400 \mathrm{mg}$ daily). This suggests that the physicians considered the recommended dose of moxifloxacin to be highly effective, without need to adjust the dose, e.g., for body weight. The lack of need for dose adjustment has the advantages of easier dosing and a reduced risk of overdosing.

The cure rates of moxifloxacin reported in the CAPRIVI study are in agreement with previous controlled studies of patients with CAP (e.g, Finch et al. [23]; Torres et al. [30]; Hoeffken et al. [26]; Petitpretz et al. [27]). Ewig et al., in the observational CAPNETZ trial of CAP patients, reported high rates of survival and low rates of treatment failure for moxifloxacin relative to $\beta$-lactam monotherapy and $\beta$-lactam combination therapy, with a particular survival benefit for moxifloxacin in patients with high CRB-65 scores [56]. The rapid recovery from symptoms observed in CAPRIVI is a desirable characteristic for an effective treatment in patients with CAP. Other clinical studies have reported that moxifloxacin is associated with more rapid recovery from symptoms than other commonly used treatments [22].

The incidences of TEAEs and drug-related TEAEs in CAPRIVI were low and no deaths occurred in patients with TEAEs. The nature and the frequency of drugrelated TEAEs (i.e., mainly gastrointestinal disorders) were consistent with the established safety profile of moxifloxacin. For most patients in the study, the TEAEs resolved during the course of treatment and were associated with low rates of treatment withdrawal (24 [0.9\%] patients in total, including 19 [0.7\%] patients with drugrelated TEAEs).

Overall satisfaction with moxifloxacin treatment was high among both physicians and patients. Physicians rated the CAP symptoms "very much improved" or "much improved" in $95.3 \%$ of patients, while $94.1 \%$ of patients were "very much satisfied" or "much satisfied" with moxifloxacin therapy.

Limitations of the current study include the primary role of physician judgment in the decisions on patient selection and management; a lower than expected proportion of high-risk patients; and the absence of a control group to quantify the response to other antibacterial agents. A strength of CAPRIVI, as with other observational studies, is that it provides an accompaniment to randomized controlled trials by reflecting real-world practice in prescribing behavior.

\section{Conclusions}

The efficacy and safety profiles of moxifloxacin characterized in this large observational study from Eastern and Central Europe and the Middle East confirm previous studies which report that moxifloxacin offers benefits in the treatment of inpatients with CAP. The high response rate in this study, which included patients with a range of disease severities, suggests that treatment with broader-spectrum drugs such as moxifloxacin is appropriate for patients with CAP who are managed in hospital.

\section{Abbreviations}

CAP: Community acquired pneumonia; TEAEs: Treatment-emergent adverse events; SD: Standard deviation.

\section{Competing interests}

$\mathbb{K}, A B, I K T, L R$, and $L I$ declare that they have no competing interests. H-PM and TP are full-time employees of Bayer AG.

\section{Authors' contributions}

$I K, A B, I K T, L R$, and $L I$ participated in data acquisition and data analysis and interpretation. H-PM and TP participated in study design and concepts, and data analysis and interpretation. All authors read and approved the final manuscript.

\section{Acknowledgments}

Bayer Pharma provided support in the design and conduct of the study and in the collection, management, and analysis of the data. The roles of the authors who are employed by Bayer Pharma are itemized in the section above.

Caroline Schneider and Klaus Hechenbichler at the Dr. Schauerte Contract Research Organization provided project management and statistical support. Bill Wolvey from PAREXEL provided medical writing support funded by Bayer Pharma.

\section{Author details}

${ }^{1}$ University of Zagreb School of Medicine, University Hospital for Infectious Diseases "Dr. Fran Mihaljević", Mirogojska cesta 8, 10000 Zagreb, Croatia. ${ }^{2}$ Military Clinical Hospital N. Burdenko, Moscow, Russia. ${ }^{3}$ University Clinic for Infectious Diseases, Medical Faculty, Skopje, Macedonia. ${ }^{4} 1$ st Department of Medicine, Military Hospital, Hungarian Defence Forces (Previously 1st Department of Medicine, National Healthcare Centre), Budapest, Hungary. ${ }^{5}$ Pulmonology Department, National Medical Academy of Postgraduate Education, City Clinic \#17, Kiev, Ukraine. ${ }^{6}$ Bayer Vital GmbH, Leverkusen, Germany. ${ }^{7}$ Bayer Pharma AG, Berlin, Germany.

Received: 19 February 2014 Accepted: 18 June 2014 Published: 30 June 2014

\section{References}

1. Wiemken $T L$, Peyrani P, Ramirez JA: Global changes in the epidemiology of community-acquired pneumonia. Semin Respir Crit Care Med 2012, 33(3):213-219.

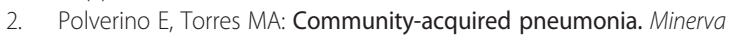
Anestesiol 2011, 77(2):196-211.

3. Almirall J, Bolibar I, Vidal J, Sauca G, Coll P, Niklasson B, Bartolome M, Balanzo X: Epidemiology of community-acquired pneumonia in adults: a population-based study. Eur Respir J 2000, 15(4):757-763. 
4. El Moussaoui R, Opmeer BC, de Borgie CA, Nieuwkerk P, Bossuyt PM, Speelman P, Prins JM: Long-term symptom recovery and health-related quality of life in patients with mild-to-moderate-severe communityacquired pneumonia. Chest 2006, 130(4):1165-1172.

5. Lim WS, Baudouin SV, George RC, Hill AT, Jamieson C, Le Jeune I, Macfarlane JT, Read RC, Roberts HJ, Levy ML, Wani M, Woodhead MA: BTS guidelines for the management of community acquired pneumonia in adults: update 2009. Thorax 2009, 64(Suppl 3):iii1-iii55.

6. Lim WS, Woodhead M: British thoracic society adult community acquired pneumonia audit 2009/10. Thorax 2011, 66(6):548-549.

7. Lode HM: Managing community-acquired pneumonia: a European perspective. Respir Med 2007, 101(9):1864-1873.

8. Watkins RR, Lemonovich TL: Diagnosis and management of communityacquired pneumonia in adults. Am Fam Physician 2011, 83(11):1299-1306.

9. Welte T, Torres A, Nathwani D: Clinical and economic burden of community-acquired pneumonia among adults in Europe. Thorax 2012, 67(1):71-79.

10. Nair GB, Niederman MS: Community-acquired pneumonia: an unfinished battle. Med Clin North Am 2011, 95(6):1143-1161.

11. Jackson ML, Neuzil KM, Thompson WW, Shay DK, Yu O, Hanson CA, Jackson $L A$ : The burden of community-acquired pneumonia in seniors: results of a population-based study. Clin Infect Dis 2004, 39(11):1642-1650.

12. Howard LS, Sillis M, Pasteur MC, Kamath AV, Harrison BD: Microbiological profile of community-acquired pneumonia in adults over the last 20 years. $J$ Infect 2005, 50(2):107-113.

13. Lieberman D, Schlaeffer F, Boldur I, Lieberman D, Horowitz S, Friedman MG Leiononen $\mathrm{M}$, Horovitz O: Multiple pathogens in adult patients admitted with community-acquired pneumonia: a one year prospective study of 346 consecutive patients. Thorax 1996, 51(2):179-184.

14. Shah BA, Singh G, Naik MA, Dhobi GN: Bacteriological and clinical profile of community acquired pneumonia in hospitalized patients. Lung India 2010, 27(2):54-57

15. Mandell LA, Wunderink RG, Anzueto A, Bartlett JG, Campbell GD, Dean NC, Dowell SF, File TM Jr, Musher DM, Niederman MS, Torres A, Whitney CG: Infectious diseases society of America/American thoracic society consensus guidelines on the management of community-acquired pneumonia in adults. Clin Infect Dis 2007, 44(Suppl 2):S27-S72.

16. Woodhead M, Blasi F, Ewig S, Garau J, Huchon G, leven M, Ortqvist A, Schaberg T, Torres A, van der Heijden G, Read R, Verheij TJ, Joint Taskforce of the European Respiratory Society and European Society for Clinical Microbiology and Infectious Diseases: Guidelines for the management of adult lower respiratory tract infections - full version. Clin Microbiol Infect 2011, 17(Suppl. 6):E1-E59.

17. Blondeau JM, Vaughan D, Laskowski R, Borsos S: Susceptibility of Canadian isolates of Haemophilus influenzae, Moraxella catarrhalis and Streptococcus pneumoniae to oral antimicrobial agents. Int J Antimicrob Agents 2001, 17(6):457-464

18. Burkhardt $\mathrm{O}$, Welte $\mathrm{T}$ : 10 years' experience with the pneumococcal quinolone moxifloxacin. Expert Rev Anti Infect Ther 2009, 7(6):645-668.

19. Miravitlles M: Moxifloxacin in respiratory tract infections. Expert Opin Pharmacother 2005, 6(2):283-293.

20. Miravitlles M, Anzueto A: Moxifloxacin: a respiratory fluoroquinolone. Expert Opin Pharmacother 2008, 9(10):1755-1772.

21. An MM, Zou Z, Shen H, Gao PH, Cao YB, Jiang YY: Moxifloxacin monotherapy versus $\beta$-lactam-based standard therapy for community-acquired pneumonia: a meta-analysis of randomised controlled trials. Int J Antimicrob Agents 2010, 36(1):58-65.

22. Anzueto A, Niederman MS, Pearle J, Restrepo MI, Heyder A, Choudhri SH: Community-Acquired Pneumonia Recovery in the Elderly (CAPRIE): efficacy and safety of moxifloxacin therapy versus that of levofloxacin therapy. Clin Infect Dis 2006, 42(1):73-81.

23. Finch $\mathrm{R}$, Schurmann D, Collins $\mathrm{O}$, Collins $\mathrm{O}$, Kubin R, McGivern J, Bobbaers $H$, Izquierdo JL, Nikolaides P, Ogundare F, Raz R, Zuck P, Hoeffken G: Randomized controlled trial of sequential intravenous (i.v.) and oral moxifloxacin compared with sequential i.v. and oral co-amoxiclav with or without clarithromycin in patients with community-acquired pneumonia requiring initial parenteral treatment. Antimicrob Agents Chemother 2002, 46(6):1746-1754.

24. Fogarty C, Grossman C, Williams J, Haverstock D, Church D: Efficacy and safety of moxifloxacin vs. clarithromycin for community-acquired pneumonia. Infect Med 1999, 16:748-763.
25. Fogarty C, Torres A, Choudhri S, Haverstock D, Herrington J, Ambler J: Efficacy of moxifloxacin for treatment of penicillin-, macrolide- and multidrug-resistant Streptococcus pneumoniae in community-acquired pneumonia. Int J Clin Pract 2005, 59(11):1253-1259.

26. Hoeffken G, Meyer HP, Winter J, Verhoef L: The efficacy and safety of two oral moxifloxacin regimens compared to oral clarithromycin in the treatment of community-acquired pneumonia. Respir Med 2001, 95(7):553-564.

27. Petitpretz $P$, Arvis $P$, Marel M, Moita J, Urueta J: Oral moxifloxacin vs high-dosage amoxicillin in the treatment of mild-to-moderate, community-acquired, suspected pneumococcal pneumonia in adults. Chest 2001, 119(1):185-195.

28. Portier H, Brambilla C, Garre M, Paganin F, Poubeau P, Zuck P: Moxifloxacin monotherapy compared to amoxicillin-clavulanate plus roxithromycin for nonsevere community-acquired pneumonia in adults with risk factors. Eur J Clin Microbiol Infect Dis 2005, 24(6):367-376.

29. Torres A, Garau J, Arvis P, Carlet J, Choudhri S, Kureishi A, Le Berre MA, Lode $H$, Winter J, Read RC: Moxifloxacin monotherapy is effective in hospitalized patients with community-acquired pneumonia: the MOTIV study - a randomized clinical trial. Clin Infect Dis 2008, 46(10):1499-1509.

30. Torres A, Muir JF, Corris P, Kubin R, Duprat-Lomon I, Sagnier PP, Hoffken G. Effectiveness of oral moxifloxacin in standard first-line therapy in community-acquired pneumonia. Eur Respir J 2003, 21(1):135-143.

31. Welte T, Petermann W, Schurmann D, Bauer TT, Reimnitz P: Treatment with sequential intravenous or oral moxifloxacin was associated with faster clinical improvement than was standard therapy for hospitalized patients with community-acquired pneumonia who received initial parenteral therapy. Clin Infect Dis 2005, 41(12):1697-1705.

32. Yuan X, Liang BB, Wang R, Liu YN, Sun CG, Cai Y, Yu XH, Bai N, Zhao TM, Cui JC, Chen LA: Treatment of community-acquired pneumonia with moxifloxacin: a meta-analysis of randomized controlled trials. J Chemother 2012, 24(5):257-267.

33. Ball P, Stahlmann R, Kubin R, Choudhri S, Owens R: Safety profile of oral and intravenous moxifloxacin: cumulative data from clinical trials and postmarketing studies. Clin Ther 2004, 26(7):940-950.

34. Drummond MF, Becker DL, Hux M, Chancellor JV, Duprat-Lomon I, Kubin R, Sagnier PP: An economic evaluation of sequential i.v./po moxifloxacin therapy compared to i.v./po co-amoxiclav with or without clarithromycin in the treatment of community-acquired pneumonia. Chest 2003, 124(2):526-535.

35. Ferrara AM: A brief review of moxifloxacin in the treatment of elderly patients with community-acquired pneumonia (CAP). Clin Interv Aging 2007, 2(2):179-187.

36. Concato J, Shah N, Horwitz Rl: Randomized, controlled trials, observational studies, and the hierarchy of research designs. $N$ Engl J Med 2000, 342(25):1887-1892.

37. Bauer TT, Ewig S, Marre R, Suttorp N, Welte T: CRB-65 predicts death from community-acquired pneumonia. J Intern Med 2006, 260(1):93-101.

38. Bont J, Hak E, Hoes AW, Macfarlane JT, Verheij TJ: Predicting death in elderly patients with community-acquired pneumonia: a prospective validation study reevaluating the CRB-65 severity assessment tool. Arch Intern Med 2008, 168(13):1465-1468.

39. Capelastegui A, Espana PP, Quintana JM, Areitio I, Gorordo I, Equrrola M, Bilbao A: Validation of a predictive rule for the management of community-acquired pneumonia. Eur Respir J 2006, 27(1):151-157.

40. Lim WS, van der Eerden MM, Laing R, Boersma WG, Karalus N, Town Gl, Lewis SA, Macfarlane JT: Defining community acquired pneumonia severity on presentation to hospital: an international derivation and validation study. Thorax 2003, 58(5):377-382.

41. Man SY, Lee N, Ip M, Antonio GE, Chau SS, Mak P, Graham CA, Zhang M, Lu G, Chan PK, Ahuja AT, Hui DS, Sung JJ, Rainer TH: Prospective comparison of three predictive rules for assessing severity of community-acquired pneumonia in Hong Kong. Thorax 2007, 62(4):348-353.

42. Zuberi FF, Khan JA: Prospective comparison of prediction rules of mortality risk for CAP in a developing country. Int J Tuberc Lung Dis 2008 12(4):447-452

43. Al-Marzouki S, Evans S, Marshall T, Roberts I: Are these data real? Statistical methods for the detection of data fabrication in clinical trials. BMJ 2005 331(7511):267-270

44. European Network of Centres for Pharmacoepidemiology and Pharmacovigilance: ENCePP Guide on Methodological Standards in Pharmacoepidemiology. 
2014. Available at: http://www.encepp.eu/standards_and_guidances/ methodologicalGuide6.shtml.

45. FDA Guidance for Industry: Oversight of Clinical Investigations - A Risk-Based Approach to Monitoring. 2013. Available at: http://www.fda.gov/ downloads/drugs/guidancecomplianceregulatoryinformation/guidances/ ucm269919.pdf. Accessed 16 July 2014.

46. Weir C, Murray G: Fraud in clinical trials: detecting it and preventing it. Significance 2011, 8(4):164-168.

47. Malathum K, Singh KV, Murray BE: In vitro activity of moxifloxacin, a new 8-methoxyquinolone, against gram-positive bacteria. Diagn Microbiol Infect Dis 1999, 35(2):127-133.

48. Soman A, Honeybourne D, Andrews J, Jevons G, Wise R: Concentrations of moxifloxacin in serum and pulmonary compartments following a single $400 \mathrm{mg}$ oral dose in patients undergoing fibre-optic bronchoscopy. J Antimicrob Chemother 1999, 44(6):835-838.

49. AVELOX (Moxifloxacin Hydrochloride) [Summary of Product Characteristics] Solution for Infusion. EMA; 2012. Available at: http://www. ema.europa.eu/docs/en_GB/document_library/Referrals_document/ Avalox_29/WC500090584.pdf. Accessed July 16, 2014

50. AVELOX (Moxifloxacin Hydrochloride) [Summary of Product Characteristics] Tablets. EMA; 2012. Available at: http://www.ema.europa. eu/docs/en_GB/document_library/Referrals_document/Avelox_6_12/ WC500013020.pdf. Accessed July 16, 2014

51. Dwyer R, Hedlund J, Darenberg J, Henriques-Normark B, Naucler P, Runesdotter S, Kalin M: Improvement of CRB-65 as a prognostic scoring system in adult patients with bacteraemic pneumococcal pneumonia. Scand J Infect Dis 2011, 43(6-7):448-455.

52. Ewig S, Bauer T, Richter K, Szenscenyi J, Heller G, Strauss R, Welte T: Prediction of in-hospital death from community-acquired pneumonia by varying CRB-age groups. Eur Respir J 2013, 41(4):917-922.

53. Levy ML, Le Jl, Woodhead MA, Macfarlaned JT, Lim WS: Primary care summary of the British thoracic society guidelines for the management of community acquired pneumonia in adults: 2009 update. Endorsed by the Royal College of General Practitioners and the Primary Care Respiratory Society UK. Prim Care Respir J 2010, 19(1):21-27.

54. Bartlett JG, Dowell SF, Mandell LA, File TM Jr, Musher DM, Fine MJ: Practice guidelines for the management of community-acquired pneumonia in adults: infectious diseases society of America. Clin Infect Dis 2000, 31(2):347-382.

55. Lutfiyya MN, Henley E, Chang LF, Reyburn SW: Diagnosis and treatment of community-acquired pneumonia. Am Fam Physician 2006, 73(3):442-450.

56. Ewig S, Hecker H, Suttorp N, Marre R, Welte T: Moxifloxacin monotherapy versus $\beta$-lactam mono- or combination therapy in hospitalized patients with community-acquired pneumonia. J Infect 2011, 62(3):218-225.

doi:10.1186/1471-2466-14-105

Cite this article as: Kuzman et al:: Efficacy and safety of moxifloxacin in community acquired pneumonia: a prospective, multicenter, observational study (CAPRIVI). BMC Pulmonary Medicine 2014 14:105.

\section{Submit your next manuscript to BioMed Central and take full advantage of:}

- Convenient online submission

- Thorough peer review

- No space constraints or color figure charges

- Immediate publication on acceptance

- Inclusion in PubMed, CAS, Scopus and Google Scholar

- Research which is freely available for redistribution

Submit your manuscript at www.biomedcentral.com/submit
Ciomed Central 